\title{
Cell therapy in the treatment of bronchiolitis obliterans in a murine model
}

\section{Terapia celular no tratamento da bronquiolite obliterante em modelo murino}

\author{
Julio de Oliveira Espinel ${ }^{1}$; Carolina Uribe ${ }^{1}$; Fabíla Schons Meyer ${ }^{1}$; Rafael Bringheti ${ }^{2}$; Jane Ulbricht Kulczynski ${ }^{1}$; \\ Maurício Guidi Saueressig ${ }^{1}$
}

A B S T R A C T

\begin{abstract}
Objective: To evaluate the importance of stem cells derived from adipose tissue in reducing graft inflammation in a murine model of allogeneic heterotopic tracheal transplant. Methods: We performed a heterotopic tracheal allografting in dorsal subcutaneous pouch and systemically injected $5 \times 10^{5}$ mesenchymal stem cells derived from adipose tissue. The animals were divided into two groups according to the time of sacrifice: T7 and T21. We also carried out histological analysis and digital morphometry. Results: The T7 animals treated with cell therapy had median obstructed graft area of 0 versus 0.54 of controls $(p=0.635)$. The treated T21 subjects had median obstructed graft area of 0.25 versus 0 in controls $(p=0.041)$. Conclusion: The systemically injected cell therapy in experimental murine model of bronchiolitis obliterans did not reduce the severity of the allograft inflammation in a statistically significant way in seven days; Conversely, in 21 days, it increased the allograft inflammatory process.
\end{abstract}

Key words: Transplantation, Heterotopic. Bronchiolitis Obliterans. Cell- and Tissue-Based Therapy. Stem Cells. Mesenchymal Stem Cell Transplantation.

\section{INTRODUCTION}

L ung transplantation has become a viable alternative for many terminal pulmonary diseases. Bronchiolitis obliterans (BO) is the main constraint to long-term survival in lung transplantation. It displays inflammatory etiology. Multiple factors contribute to the development of this condition: repeated episodes of acute rejection, cytomegalovirus infections, gastroesophageal reflux disease, primary graft dysfunction, type of transplant performed, whether unilateral or bilateral, and also aspects related to autoimmunity.

The therapeutic alternatives for BO are limited and without a clearly established protocol. Possible treatments include changing the immunosuppressive medication, photopheresis, total lymphoid irradiation, azithromycin, plasmapheresis and inhaled cyclosporine ${ }^{1,2}$. Some national initiatives have tried to move forward on this issue and many alternatives keep arising ${ }^{3.4}$.

The simplest experimental model to study BO (chronic rejection) is the allogeneic heterotopic tracheal transplantation with small rodents ${ }^{5-7}$. This model is shown to be robust to studies on immunogenesis, from the genetic and molecular points of view, and evaluation of new immunosuppressive therapies in the early stages.
Stem cells (SC) are those with self-renewal and differentiation capacity and there is a growing body of study of such cells $s^{5,8-13}$. Their role has been tested in different diseases, creating a new branch of knowledge - regenerative medicine.

It is known that mesenchymal stem cells (MSC) have immunomodulatory properties. It has been proposed that they are capable of modulating the response to ischemic injury and even attenuate the effects of immunemediated diseases. MSC have been tested in clinical trials in humans graft versus host disease scenarios after transplantation of allogeneic hematopoietic stem cells and inflammatory bowel disease ${ }^{8,9}$. In an experimental model of heterotopic tracheal transplant, Grove et al. evaluated the role of MSC derived from bone marrow and detected a significant $60 \%$ reduction in $\mathrm{BO}$ occurrence ${ }^{5}$.

Considering that $\mathrm{BO}$ is a disease of inflammatory nature, which limits the survival of lung transplantation and therapeutic options are limited, we prepared an experimental study to assess the importance of stem cells derived from adipose tissue in reducing the graft inflammatory process in a murine model of allogeneic heterotopic tracheal transplant.

1. Universidade Federal do Rio Grande do Sul - RS - Brazil; 2. Universidade Federal de Ciências da Saúde de Porto Alegre - RS - Brazil. 


\section{METHODS}

This randomized, blinded and controlled experimental study was developed at the Centro de Pesquisas of the Hospital Universitário de Porto Alegre, at the following laboratories: Unidade de Experimentação Animal, Centro de Terapia Gênica, Laboratório de Patologia Experimental e Laboratório de Vias Aéreas e Pulmão. The study was approved by the Comitê de Ética em Pesquisa of the Hospital de Clínicas de Porto Alegre under number 100524.

The handling and accommodation of the mice were in accordance with Normative Resolution 196/96 of the National Health Council, with the Care and Use of Laboratory Animals Guide of the United State National Institutes of Health (NIH publication in $85-23$, revised in 1996).

The mice were purchased from centers specialized in experimental animals. Altogether, we used 90 rats, 37 animals BalbC (receptors) and 37 C57BL6 animals (donors). We used 16 C57BL6 mice for extraction of mesenchymal stem cells. All animals were treated according to the current standard for experimental animals.

To obtain mesenchymal stem cells derived from adipose tissue, the C57BL6 mice were killed by cervical dislocation on the Animal Experimentation Unit (UEA). We removed the epididymal adipose tissue and placed it on a culture medium consisting of Dulbecco's Modified Eagle Medium, supplemented with $10 \%$ fetal bovine serum and $1 \%$ penicillin / streptomycin. This sample was transported to the Gene Therapy Center and placed in a sterile environment inside the exhaust hood. The tissue was subjected to mechanical digestion with scalpel and thereupon to enzymatic digestion with collagenase type I $(1 \mathrm{mg} / \mathrm{ml})$ for 30 minutes at $37^{\circ} \mathrm{C}$ while stirring in ten minutes. The cell suspension was centrifuged and seeded into a sixwell plate. The cell culture was maintained with culture medium. After two weeks of culture medium and subsequent exchanges, the cells obtained were called mesenchymal stem cells. When the culture reached confluence, they were treated with trypsin and transferred to culture bottles. The cells were grown till $5 \times 10^{5}$ cells aliquots were obtained by animal being treated. Each aliquot was diluted in $100 \mu$ l of phosphate buffered saline for injection in the mice.

Donor animals were anaesthetized with xylazine $10 \mathrm{mg} / \mathrm{kg}$ and ketamine $100 \mathrm{mg} / \mathrm{kg}$. After the animal did not react topainful stimulation of the hind legs, we held a longitudinal incision from the xiphoid process to the cervical region of the animal. The anterior chest wall was excised to facilitate access and dissection of the trachea, from the larynx to the main carina. We dissected the trachea, freed it from the esophagus, and subsequently withdrew the larynx, thyroid remnants and adjacent lymphoid tissues by microdissection with appropriate instruments. After excision, the entire trachea was kept in cold buffered saline (between 4 and $10^{\circ} \mathrm{C}$ ) until implantation in the receptor mouse.
The receptor was subjected to inhalation anesthesia with isoflurane in titrated dose to reach analgesia with spontaneous breathing. When the anesthesia plane was satisfactory, oxygen was offered through a hood. We preformed a longitudinal, $1 \mathrm{~cm}$ incision in the animal's torso, $5 \mathrm{~mm}$ caudal from the scapula tip at the dorsal midline. We made one subcutaneous pocket cranial to the incision by blunt dissection to place the graft (stretched entire trachea) to at least $1 \mathrm{~cm}$ cranial to the incision. Surgical synthesis was performed with nylon 6.0 sutures, with separate stitches and buried knots. Tramadol was administered $10 \mathrm{mg} / \mathrm{kg}$ in the immediate postoperative period and then the animals were sent back to cages and maintained with water and feed ad libitum.

The animals were sacrificed on the seventh and $21^{\text {st }}$ post-transplant days in a $\mathrm{CO}_{2}$ gas chamber. After sacrifice, we carried out a new incision in the recipient animal $3 \mathrm{~cm}$ caudally from the previous one and inverted the skin of the back of the animal. After identification of the graft, we dissected it from the adjacent tissue and immersed it in formalin.

Each donor C57BL6 mouse had its trachea removed and implanted in a recipient, BalbC mouse. Upon implantation, the animals were given $100 \mu$ l of cell therapy or of buffered saline through the tail vein.

The experimental groups received the following names according to treatment and the time for sacrifice: T7cel - ten animals sacrificed in seven days, treated with cell therapy; T7con - five animals sacrificed in seven days, treated with phosphate buffered saline; T21 cel -12 animals sacrificed at 21 days, treated with cell therapy; and T21 con - ten animals sacrificed at 21 days, treated with normal saline (Figure 1).

Cell therapy was administered to the animals by injection of $100 \mu \mathrm{l}$ of buffered saline with $10^{5}$ mesenchymal stem cells into the tail vein with a $30 \mathrm{G}$ needle. The injection of cell therapy solution was administered slowly over one minute. If we observed leakage of the contents, assessed by visual inspection of the tail, we would administer a new standard aliquot of $5 \times 10^{5}$ cells. Animals that died after injection of cell therapy were excluded from analysis.

For histological analysis, the tracheas, taken in specific times, were immersed in formaldehyde. Tracheas were cut in their middle portion in sections of $5 \mu \mathrm{m}$ thickness. After fixation, they were stained using hematoxylin and eosin (HE). Slides were evaluated semiquantitatively as to: 1 ) the intraluminal obliteration, classified as more or less than $50 \%$ (severe intraluminal obliteration if $>50 \%$ ); 2 ) degree of preservation of the epithelium, classified as loss of more or less than $50 \%$ of the epithelium integrity (severe epithelial loss if $>50 \%$ ); 3 ) presence of lymphocytic or plasmacytic inflammation, classified as mild (sparse infiltrate involving vessels or permeating adjacent connective tissue) or severe (diffuse infiltrate with transmural involvement); 4) circulatory disorders (vascular and extravascular), classified 
as mild or severe according to the presence of swelling or polymorphonuclear infiltration involving vasculature, classification adapted from Boehler ${ }^{14}$. The slides were also stained with picrosirius, specific for distinguishing collagen fibrils, to identify whether the graft luminal obliteration was caused by a collagen-rich tissue or not.

Digital morphometric analysis (Image J - version 1.45s) was applied to histological sections of the grafts stained with picrosirius and $\mathrm{HE}$ and scanned for image capture software (Image-Pro Express). We manually set the luminal obstruction area (A2) and the original area of the graft lumen (A1). We calculated the A2/A1 ratio, which resulted in the graft obstructed area.

We conducted sample size calculation based on the primary outcome - evaluation of the inflammatory process by the luminal obstruction, based on a pilot study. We obtained a necessary sample of five animals per group.

We conducted a normality test for the continuous variable "graft obstructed area". We found that the standard deviation exceed half the average of the sample; I had a positively skewed distribution. Thus we presented the data as median and interquartile range. For the statistical analysis, we used the Fisher's test for categorical variables. The Mann-Whitney test was used for continuous variables, since they displayed a non-normal distribution and demanded a nonparametric treatment. We included in the statistical analysis the animals that survived until the scheduled day of death, excluding animals that died before this period.

\section{RESULTS}

The analysis of the intraluminal obstruction of heterotopic grafts from sacrificed animals within seven days showed severe obliteration (for a cutoff of $50 \%$ obliteration) in $40 \%$ of animals treated with cell therapy and $50 \%$ in control animals $(p=1)$ (Table 1). Analysis of the integrity of the grafts' heterotopic epithelium showed that $50 \%$ of animals of both T7cel and T7con groups showed severe loss of epithelial integrity (loss $>50 \%$ of epithelial integrity) $(p=1)$. When analyzing lymphoplasmacytic inflammation, we found that sever inflammatory process occurred only in the T7con group (16.67\% of animals) $(p=0.38)$. Regarding circulatory disturbances (vascular and extravascular), we observed $60 \%$ of severe circulatory changes in T7cel and $100 \%$ in T7con ( $p=0.23$ ) (Table 1, Figure 2 ).

At 21 days, severe intraluminal obliteration was $41.67 \%$ in T21 cel group versus $20 \%$ in T21 con ( $p=0.38$ ). Analysis of the inflammatory response at 21 days revealed $75 \%$ severe loss of epithelial integrity in T21 cel and $90 \%$ in T21 con ( $p=0.59$ ). When examining the lymphoplasmacytic inflammation, there was $75 \%$ severe inflammation in T21 cel versus $50 \%$ in T21 con ( $p=0.38$ ). As for circulatory changes, there was $25 \%$ of severe circulatory changes in T21cel versus $40 \%$ in T21con. $(p=0.65)$ (Table 2 , Figure 3).

Digital morphometric evaluation applying Image J on scanned histological sections showed that in the sevendays grafts the median (25th percentile - 75th percentile)

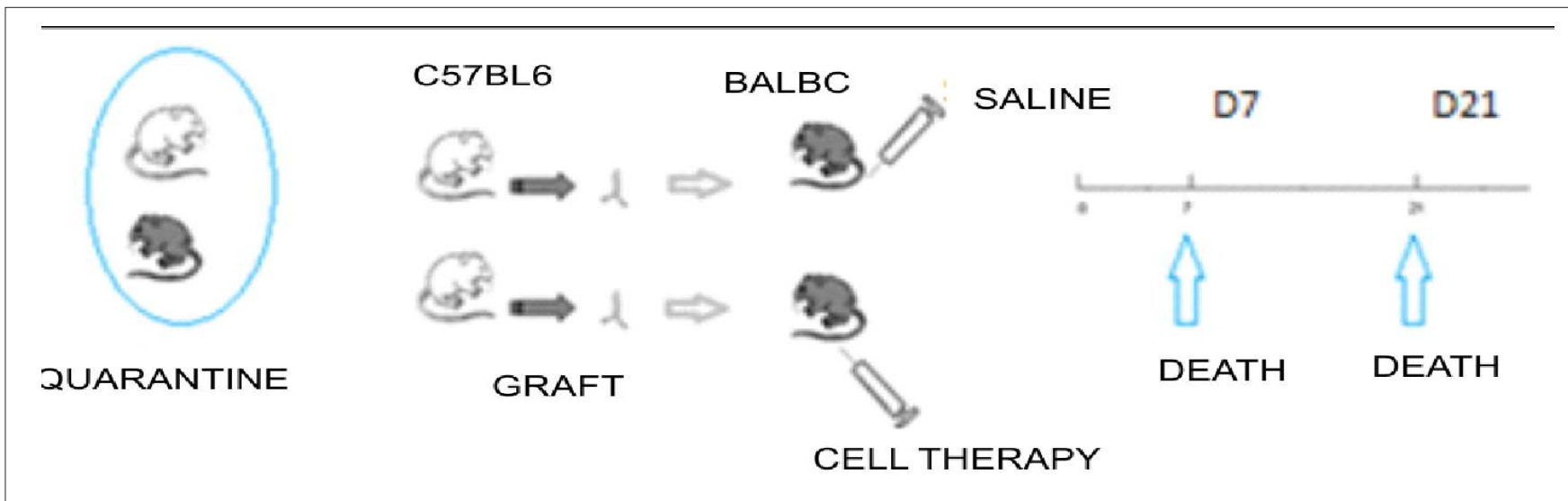

Figure 1 - Experimental design.

Table 1 - Histological analysis of animals sacrificed at seven days.

\begin{tabular}{lcrr}
\hline & T7 com & T7cel & P \\
\hline Severe intraluminal obliteration & $50 \%$ & $40 \%$ & 1 \\
Severe loss of epithelial integrity & $50 \%$ & $50 \%$ & 1 \\
Severe lymphoplasmacytic inflammation & $16,67 \%$ & $0 \%$ & 0.38 \\
Severe circulatory changes & $100 \%$ & $60 \%$ & 0.23 \\
\hline
\end{tabular}




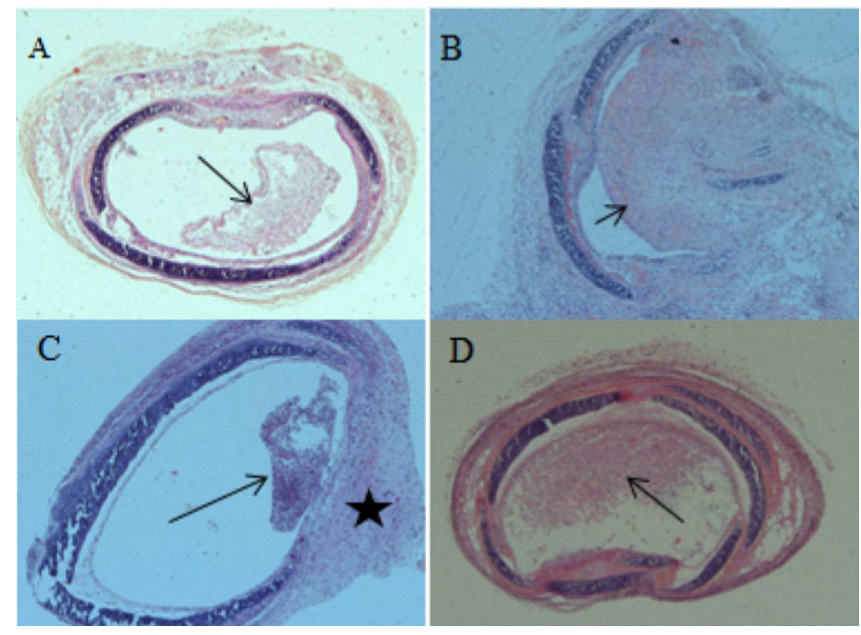

Figure 2 - $\quad$ A: photomicrograph 40x, HE. Cross section of tracheal graft in T7cel group. Partially obstructed lumen (arrow); B: photomicrograph 100x, HE. Cross section of tracheal graft in T7con group. Grafting with severe luminal obliteration (> 50\%) (arrow); $C$ : photomicrograph 100x, HE. Cross section of tracheal graft in T21cel group. Graft without severe luminal obliteration (<50\%) (arrow); lymphocytic infiltration (star). D: photomicrograph 40x, HE. Cross section of tracheal graft in T21con group. Grafting with severe luminal obliteration (<50\%) (arrow).

of the A2/A1 ratio (graft obstructed area) in T7con was 0.54 (0-0.71); in T7cel the median was 0 in (0-0.65) $(p=0.635)$ (Figure 4).

In the animals sacrificed at 21 days, the median (25th percentile - 75th percentile) of obstructed areas in T21 con was 0 (0-0.09) and in T21 cel, 0.25 (0.05-1) $(\mathrm{p}=0.041)$ (Figure 5).

\section{DISCUSSÃO}

Cell therapy with mesenchymal stem cells (MSC) shows immunomodulatory properties in several studies $^{5,6,1012,15-18}$. Bronchiolitis obliterans (BO), which is the pathological expression of the lung transplantation chronic rejection, has treatments with limited efficacy. BO has inflammatory nature, and to test the effectiveness of MSC in this scenario, the murine experimental model of

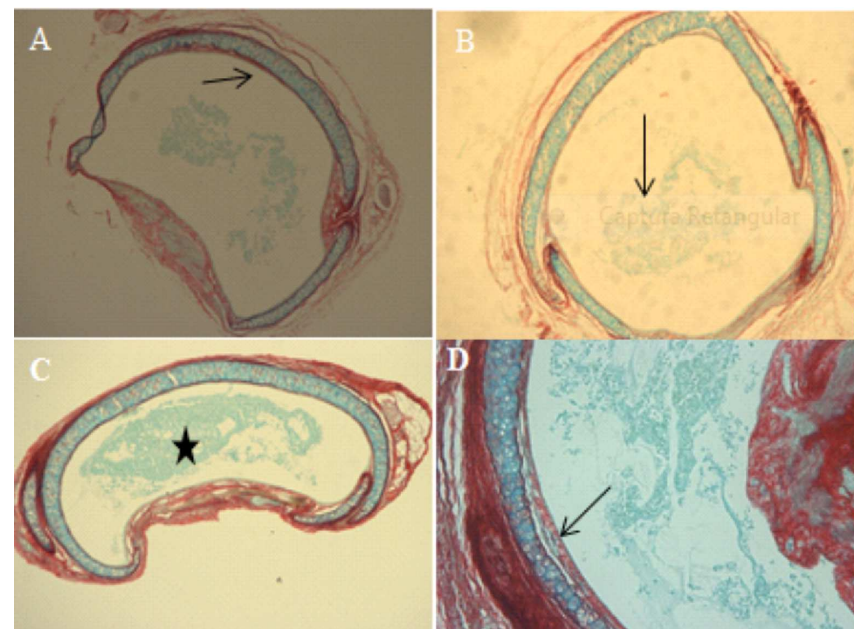

Figure 3 - A: photomicrograph 100x, picrosirius. Cross section of tracheal graft in T7cel group. Graft without severe luminal obliteration (<50\%). Arrow shows preserved epithelium. B: photomicrograph 100x, picrosirius. Cross section of tracheal graft in T7con group. Graft without severe luminal obliteration (<50\%) (arrow). C: photomicrograph 100x, picrosirius. Cross section of tracheal graft in T21cel group. Graft without severe luminal obliteration (<50\%) (star). D: photomicrograph $200 x$, picrosirius. Cross section of tracheal graft in T21 con group. Intact epithelium (arrow).

heterotopic tracheal transplant is simple and quick for the study new therapies.

Our study showed no decrease in heterotopic grafts inflammatory process in the animals treated with cell therapy and sacrificed at seven or at 21 days. We observed a slight decrease tendency in the inflammatory process at seven days, but not statistically significant.

In the digital morphometric analysis at 21 days, it is clear that the treated mice developed a larger luminal obliteration than the control group, in a statistically significant way. On the other hand, at 21 days the analysis has shown conflicting results regarding the semiquantitative evaluation of the inflammatory process. There was less severe loss of epithelial integrity and less vascular and extravascular changes in the treated group, but more severe luminal obliteration and increased lymphocytic infiltration. One must consider the limitations of a semi-quantitative analysis and the

Table 2 - Histological analysis of animals sacrificed at 21 days.

\begin{tabular}{lccc}
\hline & T21 com & T21 cel & P \\
\hline Severe intraluminal obliteration & $20 \%$ & $41.67 \%$ & 0.38 \\
Severe loss of epithelial integrity & $90 \%$ & $75 \%$ & 0.59 \\
Severe lymphoplasmacytic inflammation & $50 \%$ & $75 \%$ & 0.38 \\
Severe circulatory changes & $40 \%$ & $25 \%$ & 0.65 \\
\hline
\end{tabular}




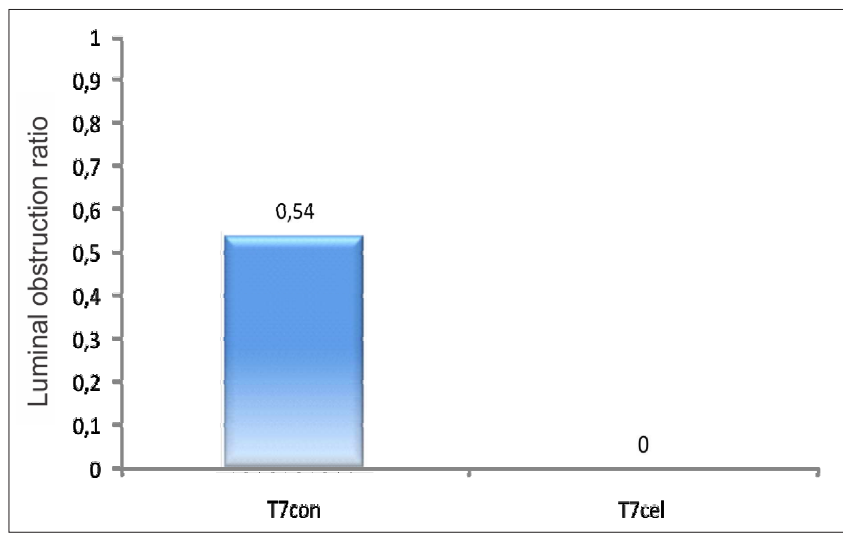

Figure 4 - $\quad$ Average of obstructed graft areas (A2/A1) at seven days; $p=0.635$. A1: area of the original graft lumen A2 graft luminal obstruction area. A2/A1: graft obstructed area

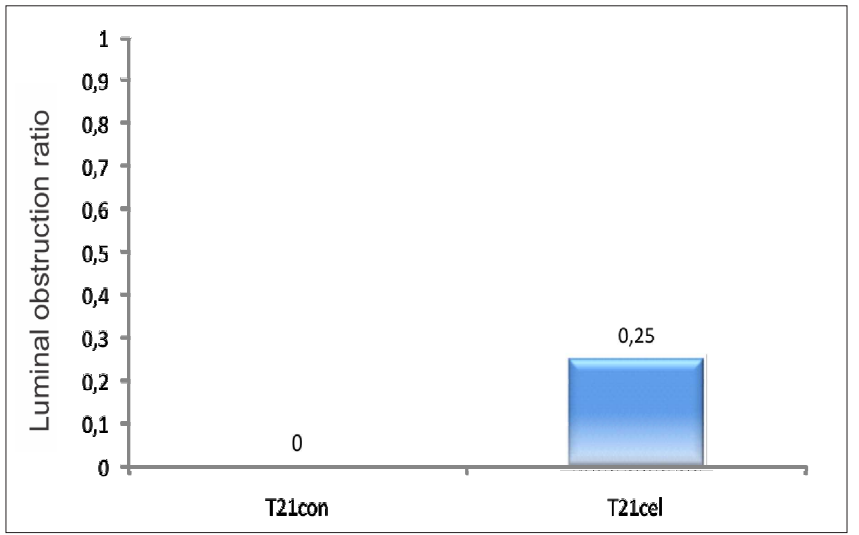

Figure 5 - $\quad$ Average of obstructed graft areas (A2/A1) at 21 days; $p=0.041$. A1: area of the original graft lumen; $A 2$ graft luminal obstruction area. A2/A1: graft obstructed area.

fact that these differences did not reach statistical significance.

Importantly, there have been reduced inflammation rates of the tracheal wall in controls at 21 days. The luminal obliteration rate at 21 days in controls' allografts was low compared to the literature. There were $20 \%$ of severe obliteration (> 50\% obstruction of the graft lumen) observed in our study against up to $75-90 \%$ reported in the literature ${ }^{7,19}$. Although we followed all surgical steps established in the literature ${ }^{14}$ and increased the number of mice in the experiment (we doubled the initially calculated sample), the intensity of luminal obliteration was consistently lower than that described in the literature. It should be noted that the murine tracheal allograft model demonstrates variability in luminal obliteration between experiments, from $30 \%$ to $100 \%$. This may account for the divergent data between different research groups ${ }^{20}$, especially with regard to luminal obliteration at 21 days $^{7}$.

The explanation for the choice of times for allografts histological analysis derived from previous studies where it is clear that the seventh day after heterotopic transplantation is the culmination of lymphocytic infiltrate in the epithelial surface (intraepithelial and subepithelial), similar to bronchitis or lymphocytic bronchiolitis seen in transplanted humans. This time is one of the earliest stages of the lung rejection process, the lymphocytic phase ${ }^{14}$. On the seventh day, we also noted lymphocytic vasculitis, which is a manifestation of rejection targeted to the endothelium. The analysis in the $21^{\text {st }}$ post-transplant day was chosen to represent the obliterative rejection phase, i.e., the terminal phase ${ }^{5}$.

By 2011, to our knowledge there was no data in the literature on MSC applied in a BO murine model. A study published in 2011 by Grove et al. ${ }^{5}$ tested a new form of immunomodulation with MSC derived from bone marrow. They carried out a retro-orbital injection of $5 \times 10^{5}$ cells on allogeneic mice. There was a decrease of $60 \%$ in the intraluminal obstruction when treated animals were compared with controls, in groups sacrificed at seven and 14 days. This suggests that cell therapy can be effective in preventing heterotopic airway obstruction.

MSC showed significant immunomodulatory properties, including in lung diseases such as chronic obstructive pulmonary disease, pulmonary hypertension, asthma and pulmonary fibrosis ${ }^{21}$. The immunomodulatory mechanisms are still not fully understood but involve the inhibition of $T$ cell proliferation and modulation of $B$ cell function ${ }^{22}$. It has been shown, too, that there is no need of MSC integrate into the injured tissues to produce effect; paracrine effects explain this phenomenon ${ }^{23}$. Still on the mode of action of MSC, it has been shown that MSC injected systemically, besides migrating to the damaged tissue by an "homing" effect, remain viable and mixed with native cells for a few months ${ }^{24}$.

While most of the literature data point to an immunomodulatory effect of MSC, some authors have demonstrated a pro-fibrotic effect of cell therapy with MSC $^{25,26}$. The reality is that MSC have a double role: they can exert an immunosuppressive function, protecting against BO through IL-8 and IL-10; or they may have a pro-fibrotic effect mediated by endothelin-1, TGF $\alpha$ and IL $13^{27}$. The local microenvironment to which MSC are exposed determines the predominant profile of their action. In our study, in animals of groups T21 con and T21cel, there was a graft luminal obliteration lower than the literature; possibly, the dosage of the cytokines involved in the inflammatory process, which was not performed, could help in the understanding of our results. This can be exploited in our next work.

We should also consider that the way to obtain the MSC can modify their immunomodulatory properties. We obtained mesenchymal stem cells from epididymal adipose tissue, unlike Grove et al. ${ }^{5}$, who obtained them from bone marrow. This, most likely, influenced our results. It is known that cells obtained from different sources have different immunomodulating potency, probably due to the 
standard production of growth factors and interleukin. The profile of inflammatory and anti-inflammatory cytokines may help to unravel the effects observed in our study ${ }^{28}$.

MSC can be obtained from several tissues: trabecular bone, periosteum, synovial membrane, skeletal muscle, skin, pericytes, peripheral blood, tooth, periodontal ligament, umbilical cord ${ }^{8}$. Adipose tissue-derived MSC have been much studied, since this tissue is abundant and capable of being accessed with low morbidity. There are reports that A-MSC have different characteristics depending on the location from which they were extracted ${ }^{8}$. Our study obtained MSC from epididymal adipose tissue. The choice was based on the experience of the gene therapy group and ease of tissue access. Another point relevant to MSC management is the source of obtaining the cells: autologous versus allogeneic; a single source or multiple sources. This seems to influence the effects of cell therapy ${ }^{9}$. Grove et al. ${ }^{5}$ obtained MSC in an allogeneic form from three different animals breeds, which may have influenced the results. There is a clinical trial demonstrating that, in some scenarios, a smaller number of cells can produce more consistent effects in terms of damaged tissues recovery ${ }^{29}$. We chose to use $5 \times 10^{5}$ cells because most of the studies in mice use this figure, although one can also use $10^{6}$ cells.

In order to analyze our results, we questioned whether a single injection at the selected time (at the time of transplantation) is the most suitable. The use of cell therapy involves test regarding both the infusion time and the number of injections. In this context, perhaps one could get different results by repeatedly applying the treatment which has not been tested to date in this model which as we know. It is also known that delayed administration of cell therapy, when the fibrotic process is already established, does not bring benefits ${ }^{9}$. However, the reversal of the initial fibrotic process has been reported after cell therapy in a pulmonary fibrosis model ${ }^{9}$.

The age of the MSC culture, as well as the number of cell expansions, determine changes in their morphology, differentiation capacity, viability, migration efficiency and competence to produce cytokines ${ }^{30}$. In our experiment, we took care to use cell cultures of the same age and the same number of expansions (four times). Hence, we do not believe that this has been the determining cause of the divergence between our results and the literature's ones.

The infusion route used in cellular therapy in murine models is variable. Injections may be intraperitoneal, locoregional and systemic via the tail vein, in the retroorbital venous plexus and through dissection of the internal jugular vein ${ }^{7}$. These different routes may determine different results, as obtained in the present study. Some works show that the first-pass metabolism by the liver sinusoids can alter the morphology and physiology of the injected cells, which does not seem to have affected this study, since the tail vein drains to the caval system, not to the portal. In addition, some groups advocate the intra-arterial route as an option for cell therapy. Thus, a larger amount of cells can reach the target tissue, reducing systemic effects ${ }^{13}$.

In a preliminary stage in our study, we tested different infusion routes: systemic injection through the tail vein, retro-ocular venous plexus and internal jugular vein. The results were not different in our pilot study. We opted for injection via the tail vein for convenience in performing a slow, technically easier injection. Still in the pilot phase, a limiting factor for the development of the experiment was the high mortality rate of animals during the cell therapy injection phase. We tested different dilutions of cell therapy (the same $5 \times 10^{5}$ cells) diluted in $50 \mu \mathrm{l}, 200 \mu \mathrm{l}$ and $100 \mu \mathrm{l}$ of buffered saline. We found no differences in mortality between groups. We chose to use $100 \mu l$, this being the most used volume in the literature. On the other hand, when we rapidly injected the MSC, they would trigger a severe respiratory insufficiency in animals, which was followed in some cases by hemiplegia and even cardiac arrest - sometimes reversible. We noted that in our study, when, in some experiments with injection of MSC, mortality ranged from 50 to $100 \%$ when we injected MSC in bolus (10 to 20 seconds). We considered that to be due to embolization of the injected cells in the right heart and brain arteries. This finding does not hold when the cell therapy is slowly injected $-100 \mu$ l over one to two minutes -, a method developed by our group. Plock et al. ${ }^{6}$ made a comment from their unpublished data, emphasizing the importance of slowly administering cell therapy.

The model applied in this experiment has many similarities to the human lung transplant. However, some aspects should always be considered: the allograft transplant is not functional, therefore not mimicking the actual environment of the transplanted tissue, sicni it is disconnected from the receiver airway; the allograft does not have its own primary vascular supply, which can impact on the dynamics of the immune response ${ }^{5}$.

Associations between pathological outcomes and molecular biology ones can determine a better understanding of the dynamics of the inflammatory process and therapy impact. Consideration should be given to analysis of the cytokines already involved in immunogenesis of bronchiolitis obliterans, as well as to attempts in associating gene expression with histopathology ${ }^{31}$.

There is a large number of publications involving murine model of heterotopic allogeneic tracheal transplantation $n^{5,7,12,14,20,25,31}$. Several immunogenesis steps were unraveled by this model. By advancing in immunogenesis, therapeutic alternatives were also tested over the past 20 years, some of them being clinically implemented, such as cyclosporin, tacrolimus, among others ${ }^{32}$.

In this context this study increases the information about cell therapy with MSC in this model, and to date, to our knowledge, this is the first experiment using MSC derived from adipose tissue for this purpose. 
As perspectives, one could test serial injections of cell therapy in animals in order to verify that a repetitive exposure could result in maximized effect in terms of reducing the inflammatory process.

Many therapeutic targets have been identified in the last decade, which increases the importance of testing immunomodulators associated with the measurement of the inflammatory process, dosing cytokines involved in the process, as well as using gene expression panels.

In conclusion, the systemically injected cell therapy in a experimental murine model of bronchiolitis obliterans did not reduce the severity of allograft inflammation in a statistically significant way at seven days; Conversely, in 21 days, it increased the allograft inflammatory process.

\section{R E S U M O}

Objetivo: avaliar a importância das células-tronco derivadas de tecido adiposo na redução do processo inflamatório no enxerto em modelo murino de transplante traqueal heterotópico alogênico. Métodos: foi realizado alotransplante traqueal heterotópico em bolsa dorsal subcutânea e injetado $5 \times 10^{5}$ células-tronco mesenquimais, derivadas de tecido adiposo, sistemicamente. Os animais foram distribuídos em dois grupos, conforme o tempo de sacrifício: T7 e T21. Procedida a análise em HE e morfometria digital. Resultados: Os T7 tratados com terapia celular apresentaram mediana de área obstruída do enxerto de 0 contra 0,54 dos controles $(p=0,635)$. Os T21 tratados apresentaram mediana de área obstruída da luz do enxerto de 0,25 nos tratados e 0 nos controles $(p=0,041)$. Conclusão: a terapia celular injetada sistemicamente em modelo experimental murino de bronquiolite obliterante não reduziu a gravidade do processo inflamatório no aloenxerto de forma estatisticamente significativa em sete dias; de modo contrário, em 21 dias, aumentou o processo inflamatório no aloenxerto.

Descritores: Transplante Heterotópico. Bronquiolite Obliterante. Terapia Baseada em Transplante de Células e Tecidos. Células Tronco. Transplante de Células-Tronco Mesenquimais.

\section{REFERENCES}

1. Morrell MR, Despotis GJ, Lublin DM, Patterson GA, Trulock EP, Hachem RR. The efficacy of photopheresis for bronchiolitis obliterans syndrome after lung transplantation. J Heart Lung Transplant. 2010;29(4):424-31.

2. Fisher AJ, Rutherford RM, Bozzino J, Parry G, Dark JH, Corris PA The safety and efficacy of total lymphoid irradiation in progressive bronchiolitis obliterans syndrome after lung transplantation. Am J Transplat. 2005;5(3):537-43.

3. Mayer E, Cardoso PF, Puskas JD, De Campos K, Oka T, Dardick I, et al. The effect of basic fibroblast growth fator and omentopexy on revascularisation and epitelial regeneration of heterotopic rat tracheal isograft. J Thorac Cardiovasc Surg. 1992;104(1):180-8.

4. Maksoud-Filho JG, Rodrigues CJ, Tannuri U, Maksoud JG. The effects of early and delayed immunosuppression in experimental tracheal transplantation with omentopexy. J Pediatr Surg. 1999;34(8):1223-8.

5. Grove DA, Xu J, Joodi R, Torres-Gonzales E, Neujahr D, Mora AL, et al. Attenuation of early airway obstruction by mesenchymal stem cells in a murine model of heterotopic tracheal transplantation. J Heart Lung Transplant. 2011;30(3):341-50.

6. Plock JA, Schnider JT, Schweizer R, Gorantla VS. Are cultured mesenchymal stromal cells an option for immunomodulation in transplantation? Front Immunol. 2013;4:41

7. Hele DJ, Yacoub MH, Belvisi MG. The heterotopic tracheal allograft as an animal model of obliterative bronchiolitis. Respir Res. 2001;2(3):169-83.

8. Mizuno H, Tobita M, Uysal AC. Concise review: Adipose-derived stem cells as a novel tool for future regenerative medicine. Stem Cells. 2012;30(5):804-10.

9. Weiss DJ, Ortiz LA. Cell therapy trials for lung diseases: progress and cautions. Am J Respir Crit Care Med. 2013;188(2):123-5.

10. Uccelli A, Moretta L, Pistoia V. Mesenchymal stem cells in health and disease. Nat Rev Immunol. 2008:8(9):726-36.
11. Burt RK, Loh Y, Pearce W, Beohar N, Barr WG, Craig R, et al. Clinical applications of blood-derived and marrow-derived stem cells for nonmalignant diseases. JAMA. 2008;299(8):925-36.

12. Guo Z, Zhou X, Li J, Meng Q, Cao H, Kang L, et al. Mesenchymal stem cells reprogram host macrophages to attenuate obliterative bronchiolitis in murine orthotopic tracheal transplantation. Int Immunopharmacol. 2013;15(4):726-34.

13. Zonta S, De Martino M, Bedino G, Piotti G, Rampino T, Gregorin $M$, et al. Which is the most suitable and effective route of administration for mesenchymal stem cell-based immunomodulation therapy in experimental kidney transplantation: endovenous or arterial? Transplant Proc. 2010;42(4):1336-40

14. Boehler A, Chamberlain D, Kesten S, Slutsky A, Liu M, Keshavjee S. Lymphocytic airway infiltration as a precursor to fibrous obliteration in a rat model of bronchiolitis obliterans. Transplantation. 1997;64(2):311-7.

15. Phinney DG, Prockop DJ. Concise review: mesenchymal stem/ multipotente stromal cells: the state of transdifferentiation and modes of tissue repair--current views. Stem Cells. 2007;25(11):2896-902.

16. English K. Mechanisms of mesenchymal stromal cell immunomodulation. Immunol Cell Biol. 2013;91(1):19-26.

17. English K, Wood KJ. Mesenchymal stromal cells in transplantation rejection and tolerance. Cold Spring Harb Perspect Med. 2013;3(5):a015560.

18. English K, Mahon BP, Wood KJ. Mesenchymal stromal cells; role in tissue repair, drug discovery and immune modulation. Curr Drug Deliv. 2014;11(5):561-71.

19. Lau CL, Zhao Y, Kron IL, Stoler MH, Laubach VE, Ailawadi G, et al The role of adenosine $\mathrm{A} 2 \mathrm{~A}$ receptor signaling in bronchiolitis obliterans. Ann Thorac Surg. 2009;88(4):1071-8.

20. Neuringer IP, Aris RM, Burns KA, Bartolotta TL, Chalermskulrat W Randell SH. Epithelial kinetics in mouse heterotopic tracheal allografts. Am J Transplant. 2002;2(5):410-9. 
21. Iyer SS, Co C, Rojas M. Mesenchymal stem cells and inflammatory lung diseases. Panminerva Med. 2009;51(1):5-16.

22. Németh K, Leelahavanichkul A, Yuen PS, Mayer B, Parmelee A, Doi $K$, et al. Bone marrow stromal cells attenuate sepsis via prostaglandin E(2)-dependent reprogramming of host macrophages to increase their interleukin-10 production. Nat Med. 2009;15(1):42-9.

23. Eggenhofer E, Benseler V, Kroemer A, Popp FC, Geissler EK, Schlitt $\mathrm{HJ}$, et al. Mesenchymal stem cells are short-lived and do not migrate beyond the lungs after intravenous infusion. Front Immunol. 2012;3:297.

24. Kuo YR, Goto S, Shih HS, Wang FS, Lin CC, Wang CT, et al. Mesenchymal stem cells prolong composite tissue allotransplant survival in a swine model. Transplantation. 2009;87(12):1769-77.

25. Salama M, Andrukhova O, Jaksch P, Taghavi S, Kelpetko W, Dekan $\mathrm{G}$, et al. Endothelin-1 governs proliferation and migration of bronchoalveolar lavage-derived lung mesenchymal stem cells in bronchiolitis obliterans syndrome. Transplantation. 2011;92(2):15562.

26. Walker N, Badri L, Wettlaufer S, Flint A, Sajian U, Krebsbach PH, et al. Resident tissue-specific mesenchymal progenitor cells contribute to fibrogenesis in human lung allografts. Am J Pathol. 2011;178(6):2461-9.

27. Hardy JD, Webb WR, Dalton ML Jr, Walker GR Jr. Lung homotransplantation in man. JAMA. 1963;186:1065-74.

28. Dimarino AM, Caplan Al, Bonfield TL. Mesenchymal stem cells in tissue repair. Front Immunol. 2013;4:201
29. Hare JM, Fishman JE, Gerstenblith G, DiFede Velazquez DL, Zambrano JP, Suncion VY, et al. Comparison of allogeneic vs autologous bone marrow-derived mesenchymal stem cells delivered by transendocardial injection in patients with ischemic cardiomyopathy: the POSEIDON randomized trial. JAMA. 2012;308(22):2369-79.

30. Hematti P. Mesenchymal stromal cells and fibroblasts: a case of mistaken identity? Cytotherapy. 2012;14(5):516-21.

31. Lemaître $\mathrm{PH}$, Vokaer $B$, Charbonnier LM, Iwakura $Y$, Field KA, Estenne $\mathrm{M}$, et al. Cyclosporine A drives a Th17- and Th2-mediated posttransplant obliterative airway disease. Am J Transplant. 2013;13(3):611-20.

32. Baughman RP, Meyer KC, Nathanson I, Angel L, Bhorade SM, Chan KM, et al. Executive summary: monitoring of nonsteroidal immunosuppressive drugs in patients with lung disease and lung transplant recipients: American College of Chest Physicians evidence-based clinical practice guidelines. Chest. 2012;142(5):1284-8.

Received on 08/07/2014

Accepted for publication 10/10/2014

Conflict of interest: none.

Source of funding: FIPE-HCPA.

Address for correspondence:

Julio de Oliveira Espinel

E-mail: julioespinel@gmail.com 